\title{
Free Lunch and Ride Sharing: A New Business Model for Winter Sport Resorts
}

\author{
Riccardo Bonazzi \\ University of Applied Sciences Western Switzerland \\ Michaël Poli \\ University of Applied Sciences Western Switzerland \\ Patrick Kuonen \\ University of Applied Sciences Western Switzerland
}

\begin{abstract}
This paper proposes a new business model for winter sport resorts, by adopting a cluster approach. By following the guidelines for design research, we propose a new online service, which combines the notions of ridesharing and rebate. Ridesharing is often seen as a solution to reduce the number of cars in winter sport resorts, whereas the delivery of discount coupon has been used to increase the amount of customers. Hence, we propose to reward skiers that share a ride with coupons of complementary activities in the winter sport resorts. We describe our proposed service by describing its customer journey.
\end{abstract}

Keywords: ridesharing, crowd sourcing, business model innovation, tourism JEL classification: L8, L9

\section{Introduction}

In this paper we describe a ridesharing solution that increases the competitiveness of regional touristic clusters in Switzerland. Hence, we start by defining the notions of (a) cluster, (b) tourism destination competitiveness and (c) ridesharing.

According to Porter (2003) clusters are geographic concentrations of interconnected companies and institutions in a particular field, which encompass an array of linked industries and other entities important to competition and whose performance of regional economies is strongly influenced by the strength of local clusters and the vitality and plurality of innovation. The approach per cluster seems a right approach of tourism activities and specificities because the resort is not a separate entity but results from the interaction, the joint actions, of many actors (Cunha and Cunha, 2005; Jackson and Murphy, 2002). In this sense, clusters represent a way of thinking about the local economies, which require the determination of new roles for companies, government, and other institutions to increase competitiveness (Porter, 2000).

The tourism destination competitiveness can be defined as the ability of a destination to attract the possible tourists to its region and satisfy their needs and wants (Enright and Newton, 2004). Destination competitiveness is determined both by tourism-specific factors and by a much wider range of factors that influence the tourism service providers. Therefore, competition occurs among touristic clusters and not among countries (Porter, 2000). When an economy is largely dependent on touristic sector, a decline in the tourism market can be devastating. In view of the importance of the Swiss tourism sector, $2.6 \%$ of the GDP (OFS, 2014), it seems necessary to avoid decline by increasing the competitiveness of regional clusters. 
The concept of ridesharing refers to the grouping of travellers into common trips by car or van (Chan and Shaheen, 2012). An example of ridesharing platform is Blablacar, which allows owner of a car to find people interested in sharing a ride towards a common destination. In recent years, a variation of ridesharing has spread among different countries: dynamic ridesharing, which allows drivers and riders to find a match in little time. The main difference between (a) ridesharing services like Blablacar and (b) dynamic ridesharing services like Uber, concerns the amount of cars needed to deliver the service and the initial investments required. For sake of comparison, we compare the total equity funding shown on crunchbase.com for Blablacar ( $\$ 330$ Million) and Uber (\$12.5 Billion).

Most ridesharing systems aim at being profitable by taking a commission fee for every money transaction. Instead, we suggest rewarding the drivers and the riders with discounts to access the services of the tourist location. By exploiting the wellknown notion of rebate, we can lower the cost of the platform, since there wouldn't be any money transaction and we suggest making money by taking a commission from every coupon used. In other words, we perform business model innovation by taking a cluster perspective and by considering the tourism destination competitiveness as key performance indicator.

Therefore, our research question is: how to combine the notions of ridesharing and rebate to increase the tourism destination competitiveness?

The rest of the paper proceeds as it follow. Section 2 briefly reviews the existing literature, whereas section 3 describes our proposed service. Section 4 concludes the paper by describing its limitations and new directions of investigation.

\section{Theoretical background}

In this section, we briefly assess the gap in the literature. In order to obtain a descriptive review of existing papers, we use the keywords "tourism competitiveness" "conceptual model" "ski resorts" cluster" on Google scholar and we selected academic articles that were available online, and we retain only the journal articles that have been cited at least twice if they are published for more than two years.

Kayar and Kozak (2010) examine the competitiveness of EU countries and Turkey based on 13 factors. These countries were clustered according to their competitiveness scores to determine the effectiveness of each factor and to rank it according to their degree of effectiveness in determining the competitiveness of destinations. Hudson et al. (2004) operationalize a model of destination competitiveness in order to measure the relative competitiveness of ski resorts in Canada. To determine the competitiveness of a destination in Egypt, Eraqi (2009) opted for a quality-centred process called Integrated Quality Management, which has five steps (1) Identify the destination partners/stakeholders, (2) Designing suitable strategies and policies, (3) Action plan, (4) Designing criteria for measurement, (5) Evaluation and adjustment. Hallmann et al. (2014) say that the destination image and the satisfaction are relevant factors for the competitiveness of the destination. The authors test empirically the applicability of a destination competitiveness model for the demand side and try to discover whether elements of destination competitiveness influence the sport tourists' perceived satisfaction with the travel experience. Hudson et al. (2004) develop a model to assess 13 ski areas, mainly in Western Canada. The five main components of the mode, ranked according to their importance are (Crouch, 2010): (1) Qualifying \& amplifying determinants; (2) Destinations policy planning \& development (3) Destination management (4) Core resources \& attractors (5) Supporting factors \& resources. 
A winter sports destination could be defined as a 'geographical, economic, and social unit consisting of all those firms, organizations, activities, areas and installations which are intended to serve the specific needs of winter sport tourists' (Hudson et al., 2004). Therefore, in a mature market, when skiers are skiing less, winter resorts must offer a more diverse range of activities, both on-snow and off-snow.

As seen in the literature, different competitiveness models have been determined to evaluate the tourism destination competitiveness. These models provide exhaustive lists of indicators/factors in which tourism clusters should have attention. However, we did not find academic articles that implement these factors to define how to use ridesharing to improve the competitiveness of a cluster.

The car is the most used mean of transport for recreation in Switzerland, and many alpine resorts are facing mobility problems, whose negative externalities include (1) traffic congestion, (2) exposure to noise and (3) air pollution (Fabbo et al., 2014). Therefore, these elements impact the tourist appeal and all economic actors' winter resorts. The majority of car drivers use two techniques to avoid congestion: (1) they take into account the traffic jams while planning their travel schedule and (2) they defer their departure time (Federal Office for Spatial Development, 2010). Nonetheless, ridesharing and other carpooling solutions can be seen as viable tools for sustainable development of mountain resorts. This form of mobility, whose services generally stem from tourist offices, is expanding within the Alps and many ski resorts seem to support this approach. Thus, we believe that carpooling helps counteract the limits of mobility solutions imposed by the topography of the stations, and it increases the attractiveness of the stations. Moreover, by reducing the travel time and waiting time, ridesharing positively impact customer satisfaction.

\section{Description of the service}

The target audience of this project is composed by alpine resorts, which experience mobility issues caused by tourists during the weekend and holiday periods. Table 1 shows how our service positively affects most of the sub-factors identified by Crouch (2010).

Table 1

Contribution of our service to the tourism destination competitiveness

\begin{tabular}{|ll|}
\hline Top 10 most important sub-factors & Contribution of our service \\
\hline Mix of activities & $\begin{array}{l}\text { Increase promotion of activities by using } \\
\text { rebates }\end{array}$ \\
\hline Culture and history & None \\
\hline Tourism superstructure & Improves management of superstructure \\
\hline Safety/security & Decreases car accidents \\
\hline Cost/value & Lowers transportation costs \\
\hline Accessibility & Increases accessibility by pooled car \\
\hline Special events & Can increase promotion of special events \\
\hline Awareness/image & Can allow promotion of unknown location \\
\hline Location & Can improve location \\
\hline
\end{tabular}

Source: Crouch, 2010 
Figure 1

Example of use case of our service
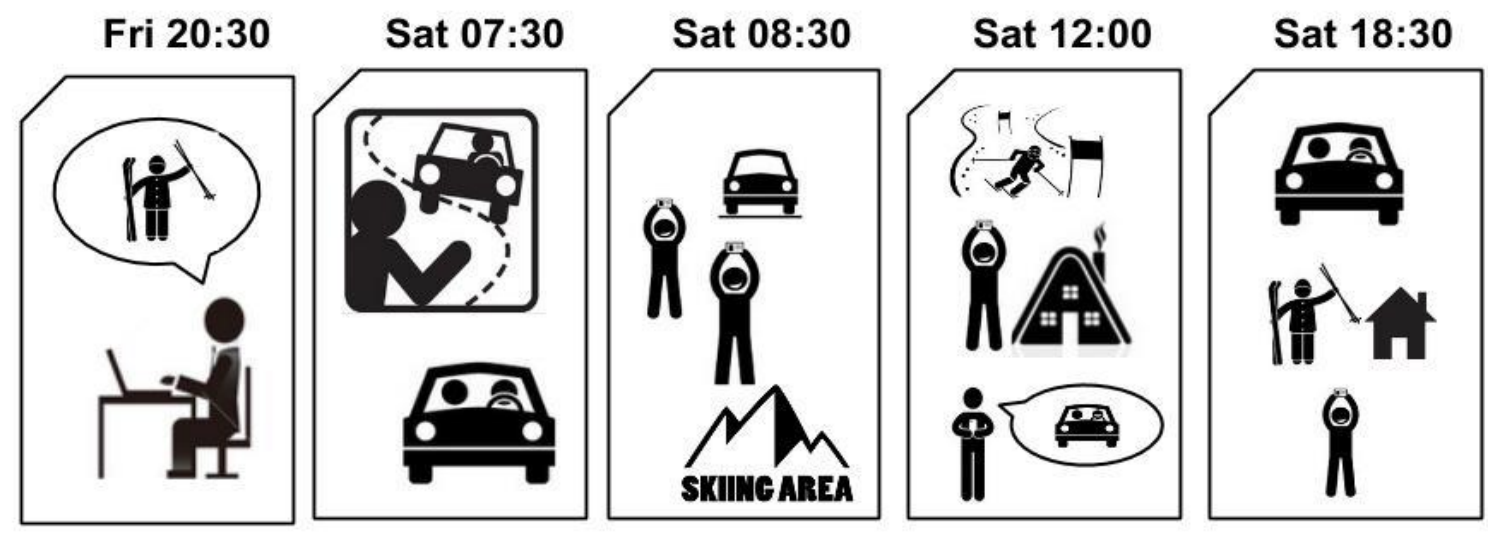

Source: Authors

Figure 1 shows an example of how our service could be used. In this example, we consider the interaction between three tourists (A=Alice, B=Benjamin and $\mathrm{C}=$ Charles), that uses a ridesharing platform to lower their transportation cost.

\section{Friday night (20:30):}

Benjamin lives in Martigny and wants to go skiing in Crans-Montana on Saturday morning. He does not want to take a train, because he has his skiis to carry, but he wouldn't like to use his car either. He goes on a ridesharing platform, where he enters the date and the destination. Benjamin finds Alice from Lausanne and fixes a meeting with her.

\section{Saturday morning (7:30):}

Alice stops in Martigny to pick Benjamin up. They make the trip to Crans-Montana. After the journey, Benjamin assigns a score to the service.

\section{Saturday morning (8:15):}

Benjamin and Alice are rewarded by the ridesharing platform for their commitment. Benjamin can choose among a $20 \%$ discount on the daily ski pass or for a menu in a nearby restaurant to ski slopes. Alice has a $30 \%$ discount on the two options, because she was the driver.

\section{Saturday afternoon (12:00):}

After a morning of skiing, Benjamin decides to have the discounted menu at the restaurant. During the meal, Benjamin goes on the ridesharing platform and search for a ride back home. He finds Charles, he fixes a meeting at 17:30 and he goes back to skiing.

\section{Saturday evening $(18: 30)$ :}

Benjamin goes back with Charles and after the ride he gives a score on the ridesharing platform. When he arrives home, Benjamin gets a rebate, to be used within the following 10 days (a $20 \%$ discount for a daily ski pass in Crans-Montana).

For sake of simplicity, the ridesharing platform is assumed to be able to (a) perform matchmaking among drivers and riders and (b) to manage the rebates. 
Nonetheless, a simpler solution would be to use an existing ridesharing platform, such as Blablacar, and to develop only the system to manage the rebates.

\section{Discussions and conclusions}

In this paper, we present an example of business model innovation that (a) uses a cluster perspective to redefine an existing problem, (b) combines together concepts coming from logistics (ridesharing) and marketing (rebate) to deliver a new solution and (c) considers the tourism destination competitiveness as a better performance indicator.

Since our work is still in progress, we are not going to present empirical data to support our intuitions. Therefore, the lack of empirical evidences can be seen as the major shortcoming of this article.

Nonetheless, our idea is grounded in previous research, which has been conducted by previous scholar and that we wish to further extend with our study in the future. Moreover, this paper aims at bridging together two fields (logistics and marketing) in order to open new directions of investigations for scholars in innovation management for tourism.

In the future, we intend to test our model in a real scenario to assess its feasibility and its return on investment.

\section{References}

1. Chan, N.D., Shaheen, S.A. (2012), "Ridesharing in North America: Past, present, and future", Transport Reviews, Vol. 32 No. 1, pp. 93-112.

2. Crouch, G.I. (2010), "Destination Competitiveness: An Analysis of Determinant attributes", Journal of Travel Research, available at: http://jtr.sagepub.com/content/early/2010/03/19/0047287510362776.abstract (12/2/2015)

3. Cunha, S.K. da, Cunha, J.C. da. (2005), "Tourism cluster competitiveness and sustainability: proposal for a systemic model to measure the impact of tourism on local development", BAR-Brazilian Administration Review, Vol. 2 No. 2, pp. 47-62.

4. Enright, M.J., Newton, J. (2004), "Tourism destination competitiveness: a quantitative approach", Tourism Management, Vol. 25 No. 6, pp. 777-788.

5. Eraqi, M.I. (2009), "Integrated Quality Management and Sustainability for Enhancing the Competitiveness of Tourism in Egypt", International Journal of Services and Operations Management, Vol. 5 No. 1, pp. 14-28.

6. Fabbo, D., Dessemontet, P., Giacomel, G., Kaufmann, V., Diaz, A.M., Munafò, S., Pini, G. (2014), "La Mobilité Des Genevois et Des Vaudois", EPFL, Lausanne, available at: http://mrmt.epfl.ch/MRMT-2010-Rapport_technique_MFO_20_03.pdf (2/3/2016)

7. Federal Office for Spatial Development. (2010), "Microcensus on Mobility and Transport 2010", Federal Office of Statistics, Neuchatel, available at: http://www.are.admin.ch/dokumentation/00121/00224/index.htmlelang=en\&msgid $=44450(25 / 6 / 2016)$.

8. Hallmann, K., Müller, S., Feiler, S. (2014), "Destination competitiveness of winter sport resorts in the Alps: how sport tourists perceive destinations?", Current Issues in Tourism, Vol. 17 No. 4, pp. 327-349.

9. Hudson, S., Ritchie, B., Timur, S. (2004), "Measuring destination competitiveness: An empirical study of Canadian ski resorts", Tourism and Hospitality Planning \& Development, Vol. 1 No. 1, pp. 79-94.

10. Jackson, J., Murphy, P. (2002), "Tourism Destinations as Clusters: Analytical Experiences from the New World", Tourism and Hospitality Research, Vol. 4 No. 1, pp. 36-52.

11. Kayar, Ç.H., Kozak, N. (2010), "Measuring destination competitiveness: an application of the travel and tourism competitiveness index (2007)", Journal of Hospitality Marketing \& Management, Vol. 19 No. 3, pp. 203-216. 
12. OFS (2014), "Ełat de santé et maladies - Données, indicateurs - Diabète", available at: http://www.bfs.admin.ch/bfs/portal/fr/index/themen/14/02/01/key/02/03.html (3/8/ 2015).

13. Porter, M.E. (2000), "Location, Competition, and Economic Development: Local Clusters in a Global Economy", Economic Development Quarterly, Vol. 14 No. 1, pp. 15-34.

14. Porter, M.E. (2003), "The Economic Performance of Regions", Regional Studies, Vol. 37 No. 6-7, pp. 545-546.

\section{About the authors}

Riccardo Bonazzi is a professor at the institute of entrepreneurship and management at HES-SO Valais. His main interests are business model design and he has conducted research on governance, risk and compliance management. The author can be contacted at riccardo.bonazzi@hevs.ch.

Michaël Poli is a research assistant at the institute of entrepreneurship and management at HES-SO Valais. He has been applying design thinking in projects with small and medium enterprises as well as start-ups. The author can be contacted at michael.poli@hevs.ch.

Patrick Kuonen is a professor at the institute of entrepreneurship and management at HES-SO Valais. He has worked for a multinational audit firm, and he has been leading projects with small and medium enterprises in the tourism sector. The author can be contacted at patrick.kuonen@hevs.ch. 